\title{
Reducing phytophthora fruit rot in eggplant and tomato fruits using rice straw and swine manure
}

\section{Alberto $\mathrm{RT}^{1^{*}}$ and Sanogo $\mathrm{S}^{2}$}

\author{
${ }^{1}$ Department of Crop Protection, Central Luzon State University, Muñoz, Nueva Ecija, Philippines \\ ${ }^{2}$ Department of Entomology, Plant Pathology, and Weed Science, New Mexico State University, Las Cruces, NM \\ 88003, USA
}

Alberto RT, Sanogo S 2012 - Reducing phytophthora fruit rot in eggplant and tomato fruits using rice straw and swine manure. Plant Pathology \& Quarantine 2(2), 153-160, doi 10.5943/ppq/2/2/8

This study was conducted in a field plot to determine the effects of rice straw and swine manure on the incidence and severity of Phytophthora fruit rot on eggplant and tomato fruits in Nueva Ecija, Philippines. Treatments were based on the presence or absence of rice straw in combination with swine manure applied at $0 \mathrm{~kg} / \mathrm{m}^{2}, 0.5 \mathrm{~kg} / \mathrm{m}^{2}$, and $1 \mathrm{~kg} / \mathrm{m}^{2}$. Plots were artificially infested with $P$. infestans. Disease incidence and severity as well as marketable yields, were assessed at intervals. In both eggplant and tomato, lowest incidence and severity of Phytophthora fruit rot occurred in plots incorporated with rice straw $\left(0.5 \mathrm{~kg} / \mathrm{m}^{2}\right)+$ high swine manure $\left(1 \mathrm{~kg} / \mathrm{m}^{2}\right)$. The overall reduction on the incidence of the disease compared to plots without rice straw and swine manure was approximately $85 \%$ in eggplant and $72 \%$ in tomato. Similarly, the overall reduction on the severity in eggplant and tomato was $80 \%$ and $67 \%$, respectively. Highest marketable yield was obtained in plants grown in plots incorporated with rice straw $\left(0.5 \mathrm{~kg} / \mathrm{m}^{2}\right)+$ high swine manure $\left(1 \mathrm{~kg} / \mathrm{m}^{2}\right)$. Other than the control, the incidence and severity were highest in eggplant and tomato plots where only rice straw was used as mulch.

Key words - Disease - farm waste - soil-borne fungi - solanaceous crops

\section{Article Information}

Received 9 September 2012

Accepted 13 September 2012

Published on line 30 September 2012

*Corresponding Author : Ronaldo T. Alberto - bertyx1275@ hotmail.com

\section{Introduction}

Nueva Ecija is the leading rice producing province in the Philippines. Following rice harvest, most farmers left behind the rice straws but failed to scatter this waste in the field. Few weeks after harvest, most farmers burn the rice straws and incorporate the burned waste into the soil during the next land preparation. Burning these wastes drives away rodents and prevents them from colonizing the field. Unknowingly for the farmers, however, such practice contributes to climate change as well as posing health hazards to the community. In addition to rice production, farmers in Nueva Ecija are also engaged in small-scale swine production, and produce vegetables such as eggplant, pepper, tomato, melon, and watermelon. This small scale swine production, however, also generates farm wastes like manures which are not properly disposed. Farmers normally dispose their swine manures in their backyard, 
irrigation drainage, canals and creeks that contributes to foul odor, unsanitary conditions and the risk of spread of animal pathogens in the community. Though this backyard swine production and rice-based vegetable production greatly contributed to sustainable food production, it also pollutes and makes the environment filthy and unsanitary place to live.

The negative effects brought about by farm wastes to the environment and the community can be off-set, however, by utilizing these wastes in agricultural production to improve soil fertility. Moreover, since a wide variety of composted materials generated from animal waste materials have been shown to suppress plant diseases (Chen et al. 1987, 1988, Hadar and Mandelbaum,1992, Aryantha et al. 2000), it is suggested that they can also be utilized as biocontrol materials against pathogens causing diseases of economic crops. Among these agricultural wastes, the composted and non-composted swine manures are commonly used by the vegetable farmers. Diab et al. (2003) showed the effective use of composted swine manure in suppressing soilborne diseases in cucumber caused by Phythium, Phytophthora and Rhizoctonia pathogens.

Rice-based vegetable production is a very common practice in Nueva Ecija, solanaceous crops, crucifers and cucurbits are vegetables commonly grown after rice, and among these groups of commodities, solanaceous crops especially eggplant and tomato are habitually grown side by side with onion shallot. Yields of these crops, however, are reduced by Phytophthora infection by as much as $25-30 \%$ every cropping season. Phytophthora species attack a wide range of plants and are responsible for some of the world's most destructive plant diseases e.g. the European potato famine caused by Phytophthora infestans (Bourke, 1964). Phytophthora diseases are also very common throughout the tropical regions of the world and cause significant losses in many tropical fruit crops and vegetables (Drenth and Sendall, 2001). Phytophthora fruit rot is one of the serious problems encountered in the cultivation of eggplant and tomatoes in Nueva Ecija. It is so widespread in the area such that most of the fields are infected amid intermittent spraying of fungicides. Failure of the farmers to correctly follow the label instructions of the fungicides also contributes to the spread of the disease. In tomato, all aboveground parts may show symptoms. Invasion of the fruit by the fungus occur at any stage of fruit development, often beginning at the stem end later forming olive-brown lesions with rough surface. In eggplant, fruit invasion occur at fruit end near the soil line and progresses upward resulting in fruit rot. Under moist condition, a white mycelia growth appears in the lesions.

The impetus for this project emanated from research information indicating that Phytophthora diseases may be controlled by the use of rice straw mulch and swine manures (Ellis et al. 1998, Fichtner et al. 2004). This research will benefit farmers in at least three ways by providing (i) a sustainable avenue for reducing Phytophthora fruit rot by utilizing farm-generated by-products, (ii) an environment friendly approach of managing rice straw other than burning in the fields and (iii) utilization of composted swine manure to minimize health risk and improve sanitary conditions in the community.

\section{Materials and Methods}

\section{Collection, Isolation and Maintenance of Isolates}

Isolates of Phytophthora infestans from different tomato and eggplant growing areas of Nueva Ecija were used in the study. The isolates of were obtained by putting infected tomato and eggplant fruit samples in a shallow layer of distilled water for 48 hours in the light at $25^{\circ} \mathrm{C}$ to induce sporangial development. Small pieces of infected plant tissue were cut off, surface sterilized in $70 \%$ ethanol for 50 seconds and blotted dry between sterile filter papers prior to transfer to previously plated V8 juice medium. The plates were examined regularly for the slow emergence of nonseptate hyphae until spores were produced for microscopic examination. The non-septate hyphae and spores were transferred to new V8 juice plates and incubated at $20-25^{\circ} \mathrm{C}$ for $10-15$ days until colonies were visible on the isolation plates. After confirmation of the identity of the isolates, pure culture of the pathogen was obtained by transferring parts of the non- 


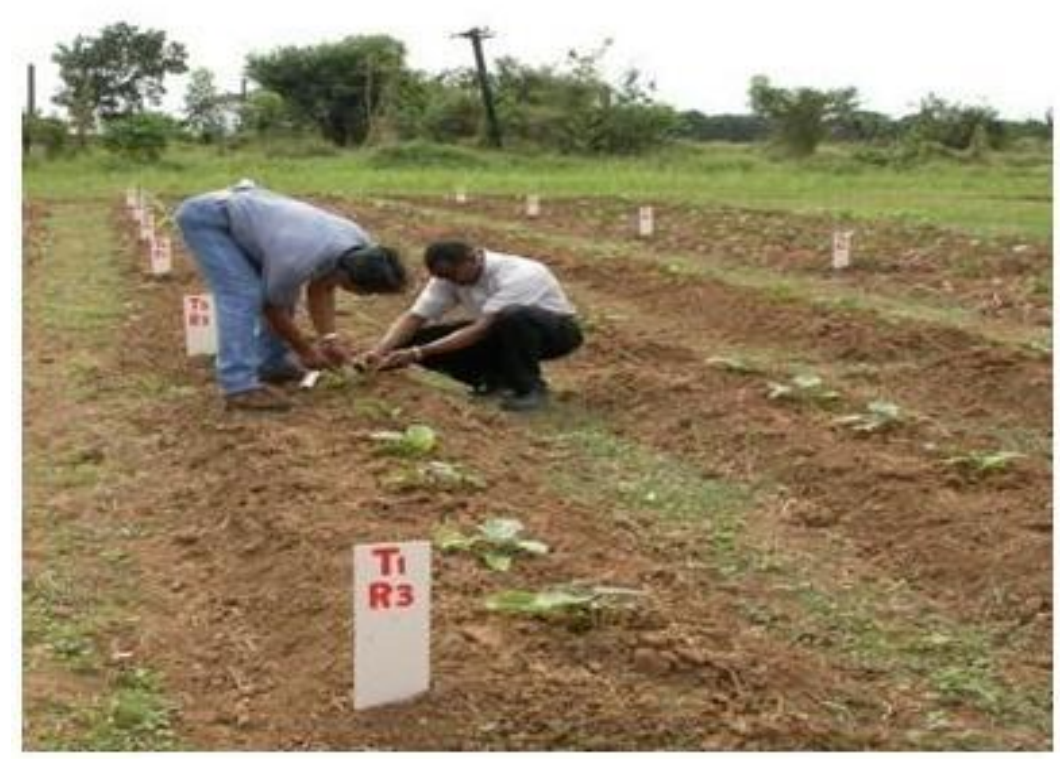

Fig. 1 - The experimental site at Central Luzon State University. Alberto (left) and Sanogo (right) examining plants in one of the eggplant plots.

septate hyphae and spores to V8 juice slants, incubated at $20-25^{\circ} \mathrm{C}$ for more than a week prior to refrigeration.

\section{Pathogenicity Tests}

Sporangiospores of P.infestans were harvested from culture plates by flooding the plates with distilled water for a few hours. Five detached healthy tomato fruits coming from the same variety where the pathogen was isolated were placed in $30.5 \mathrm{~cm} \times 61.0 \mathrm{~cm}$ double layer plastic moist chamber. The fruit samples were placed in the first layer with a perforated base lined with paper towels, below is the base mounted with water to maintain high moist conditions. A small drop (10-15 uL) of fungal suspension containing $10^{4}$ sporangia/mL was inoculated in four of the five detached tomato fruits stuck into foam to avoid premature fruit dehydration. A small drop of sterile distilled water was inoculated on the 5th fruit which serve as the control. Similar set up was provided for the eggplant fruits. Symptom development was recorded $72 \mathrm{hrs}$ after inoculation. To satisfy Koch's postulates, the pathogen was re-isolated from the artificially inoculated tomato and eggplant fruits and rechecked for its identity.

\section{Field Experiments}

Experiments were conducted in experimental farm of the College of Agriculture, Central Luzon State University in Nueva Ecija using tomato (c.v. Marimar, East West Seed Co.) and eggplant (c.v. Casino, East West Seed Co.) transplants (Fig. 1). Plots were artificially infested with an isolate of $P$. infestans. The inoculum was prepared by culturing the pathogen on sterile rice hulls on $500 \mathrm{ml}$ bottle mixed with $\mathrm{V} 8$ juice for three weeks. Two factors were examined: (i) presence or absence of rice straw and (ii) noncomposted swine manure applied at three levels: i.e. a) none $\left(0 \mathrm{~kg} / \mathrm{m}^{2}\right)$, b) low $(0.5$ $\mathrm{kg} / \mathrm{m}^{2}$, equivalent to 5 tonnes per hectare), and c) high $\left(1 \mathrm{~kg} / \mathrm{m}^{2}\right.$, equivalent to 10 tonnes per hectare). These two factors were combined to generate six treatments, namely:

1) no rice straw and no swine manure

2) rice straw $\left(0.5 \mathrm{~kg} / \mathrm{m}^{2}\right)+$ low swine manure $\left(0.5 \mathrm{~kg} / \mathrm{m}^{2}\right)$

3) rice straw $\left(0.5 \mathrm{~kg} / \mathrm{m}^{2}\right)+$ high swine manure $\left(1 \mathrm{~kg} / \mathrm{m}^{2}\right)$

4) no rice straw + low swine manure $(0.5$ $\mathrm{kg} / \mathrm{m}^{2}$ )

5) no rice straw + high swine manure (1 $\mathrm{kg} / \mathrm{m}^{2}$ ), and

6) rice straw only $\left(0.5 \mathrm{~kg} / \mathrm{m}^{2}\right)$.

The experiments, consisting of six treatments, were laid out in a randomized complete block design with four replications. 
The plot size was $1 \mathrm{~m} \times 4 \mathrm{~m}$, with $1 \mathrm{~m}$ spacing between hills for eggplant and $0.75 \mathrm{~m}$ spacing between rows and hills for tomato. A $1 \mathrm{~m}$ gap was provided between plots. Plots were manually irrigated as needed. Rice straw and non-composted swine manure were incorporated in soil when the inoculum was already three weeks old. Following incorporation, a furrow was opened at the center of each bed, and the inoculum of $P$. infestans was applied into the furrow at the rate of $100 \mathrm{~cm}^{3}$ of infested rice hull/m of row. The furrow was immediately covered with a thin layer of soil followed by manual sprinkler irrigation to hasten the decomposition of the manure in the soil. The plots were manually irrigated daily. Two weeks, thereafter, each furrow was re-opened, and 30 days old tomato and 45 days old eggplant seedlings were transplanted into the furrow.

Except for disease management practices, the eggplant and tomato were grown and maintained according to standard agronomic and management practices. Leaf miners were controlled by application of Trigard ${ }^{\circledR}$ 75WP $(5-7 \mathrm{~g} / 16 \mathrm{~L})$ and the fruit borers through hand picking. Hand weeding was dependent on the population of the weeds. Plants were monitored regularly for plant growth and health. Data was collected based on the following parameters: (i) $\%$ disease incidence defined as the percentage of fruits with Phytophthora rot (ii) \% disease severity as the percentage of fruit surface with rot symptoms and (iii) marketable fruit yield expressed as:

$$
\begin{aligned}
& \% \text { Disease Incidence }(\mathrm{DI})=\frac{\text { No. of infected fruits/plot }}{-\mathrm{Total} \text { no. of fruits/plot }} \\
& \% \text { Disease Severity }(\mathrm{DS})=\frac{\mathrm{n}(1)+\mathrm{n}(3)+\mathrm{n}(5)+\mathrm{n}(7)+\mathrm{n}(9)}{\mathrm{N} \text { x } 9}
\end{aligned}
$$

Where: $\mathrm{n}=$ No. of infected fruits classified by grade

$\mathrm{N}=$ Total number of samples

Percent disease incidence (\%DI) and percent disease severity (\%DS) were taken from each fruit per plot and rated according to the scale (Table 1): The area under the disease progress curve (AUDPC) for each treatment was computed using the following formula:

Table 1 Rating scale used in the assessment of phytophthora fruit rot in eggplant and tomato.

\begin{tabular}{cc}
\hline Scale & \% Fruit Surface Affected \\
\hline 1 & $0-1$ \\
2 & $1-3$ \\
3 & $3-6$ \\
4 & $6-12$ \\
5 & $12-25$ \\
6 & $25-50$ \\
7 & $50-75$ \\
8 & $75-100$ \\
\hline
\end{tabular}

$$
\begin{aligned}
& \mathrm{n} \\
\text { AUDPC } & =\sum[(\mathrm{Yi}+\mathrm{n} 1+\mathrm{Yi}) / 2][\mathrm{Xi}+1-\mathrm{Xi}] \\
\mathrm{i} & =1 \\
\text { Where: } \mathrm{Yi} & =\text { anthracnose severity (per unit) } \\
\mathrm{Xi} & =\text { time (days) } \\
\mathrm{n} & =\text { total no. of observation }
\end{aligned}
$$



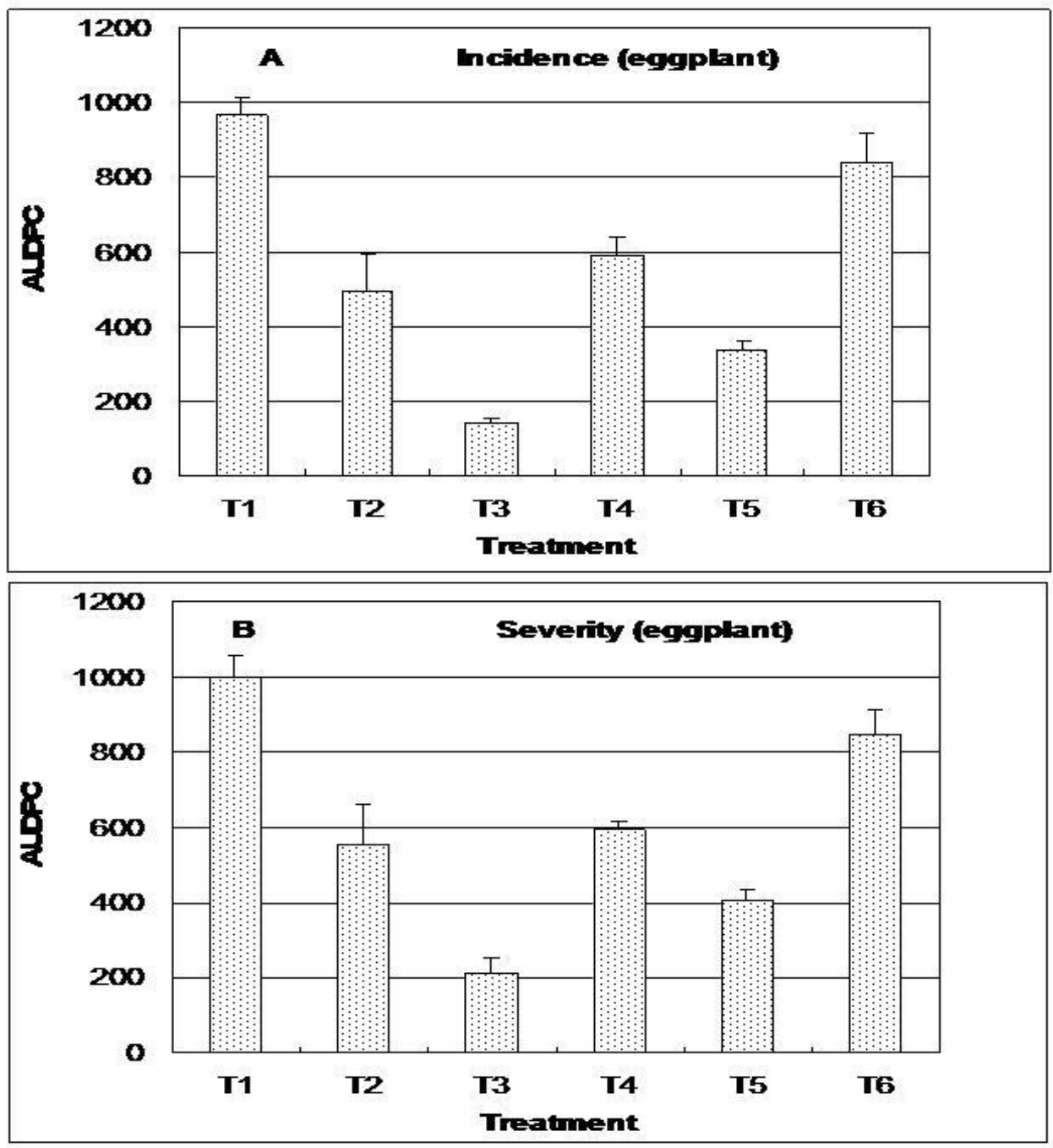

Fig. 2 - Area under disease progress (AUDPC) based on (A) disease incidence and (B) disease severity on fruit of eggplant grown under six treatments. T1: no rice straw and no swine manure; T2: rice straw and low swine manure; T3: rice straw and high swine manure; T4: no rice straw, and low swine manure; T5 -no rice straw, and high swine manure; and T6: rice straw only. Bars on columns are standard errors of the mean.

Weights of marketable fruits were gathered and recorded. Damaged and rotten fruits were discarded. Overall, five weekly primings (harvesting of matured fruits) were completed in tomato plots and nine primings in the eggplant plots. Data collected was analyzed using analysis of variance for a randomized complete block design using SAS GLM procedure, and means separation was achieved using Fischer's protected LSD.

\section{Results}

\section{Pathogenicity Test}

The isolates of $P$. infestans were found to be pathogenic to both tomato and eggplant fruits. The inoculated fruits of tomato develo- ped olive-brown lesions with rough surface. In eggplant, white mycelial growth appeared in rotting fruit; these are symptoms similar to those observed on samples collected 7 days after inoculation. Fruits inoculated with sterile distilled water remained healthy and unblemished. Based on the morphological characteristics of the re-isolated fungal pathogens from inoculated fruits, the reisolated pathogen have the same characteristics and identity with the pathogen used during the inoculation process.

\section{Eggplant experiment}

Disease incidence and disease severity were significantly different among the six treatments $(P \leq 0.0001)$. The area under 

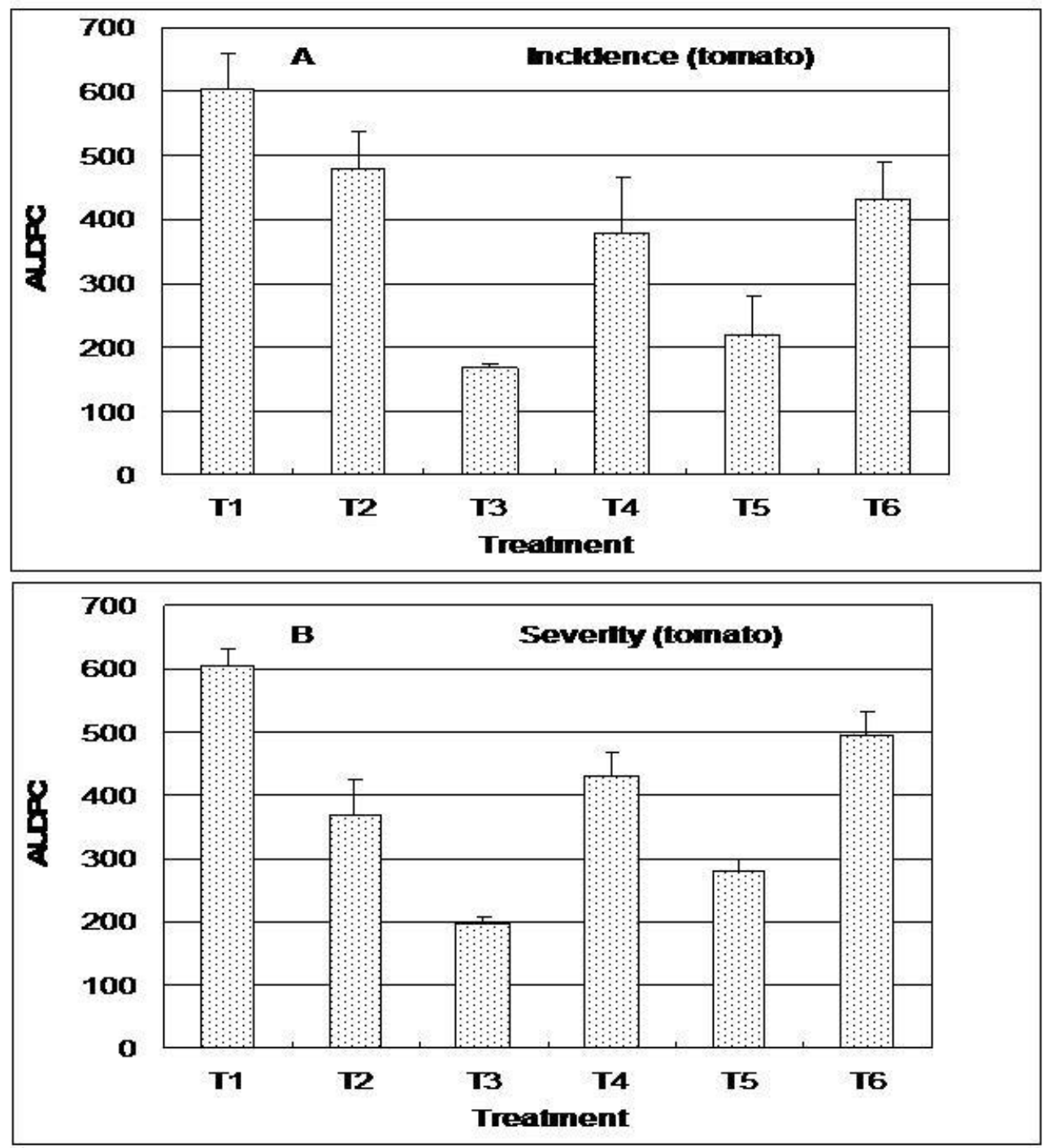

Fig. 3 - Area under disease progress (AUDPC) based on (A) disease incidence and (B) disease severity on fruit of tomato grown under six treatments. T1: no rice straw and no swine manure; T2: rice straw and low swine manure; T3: rice straw and high swine manure; T4: no rice straw, and low swine manure; T5 -no rice straw, and high swine manure; and T6: rice straw only. Bars on columns are standard errors of the mean.

disease progress curve (AUDPC, Fig. 2A) on the incidence of the disease was approximately $85 \%$ lower in treatment 3 (T3, rice straw and high swine manure) than in treatment 1 (T1, no rice straw and no swine manure). Similar results were obtained with regards to the AUDPC on disease severity (Fig 2B). The severity of the disease in T3 was approximately $80 \%$ lower than T1. Cumulative marketable yield was approximately $143 \%$ higher in T3 than T1 (Fig. 4A).

\section{Tomato experiment}

Similar to the eggplant experiment, disease incidence and disease severity were significantly different among the six treatments $(P \leq 0.002)$. The area under disease progress curve on disease incidence (AUDPC, Fig. 3A) was lowest in treatment 3 (T3, rice straw + high swine manure) and greatest in treatment 1 (T1, no rice straw and no swine manure). The AUDPC based on incidence data, was approximately $72 \%$ lower in $\mathrm{T} 3$ than in $\mathrm{T} 1$.

Similar results were obtained with regards to the AUDPC on disease severity. The AUDPC in T3 was lower (approximately 67\%) than T1 (Fig. 3B). Cumulative marketable yield was highest under treatment 3 and lowest under treatment 1. Marketable yield in T3 was 260\% higher than T1 (Fig. 4B). 

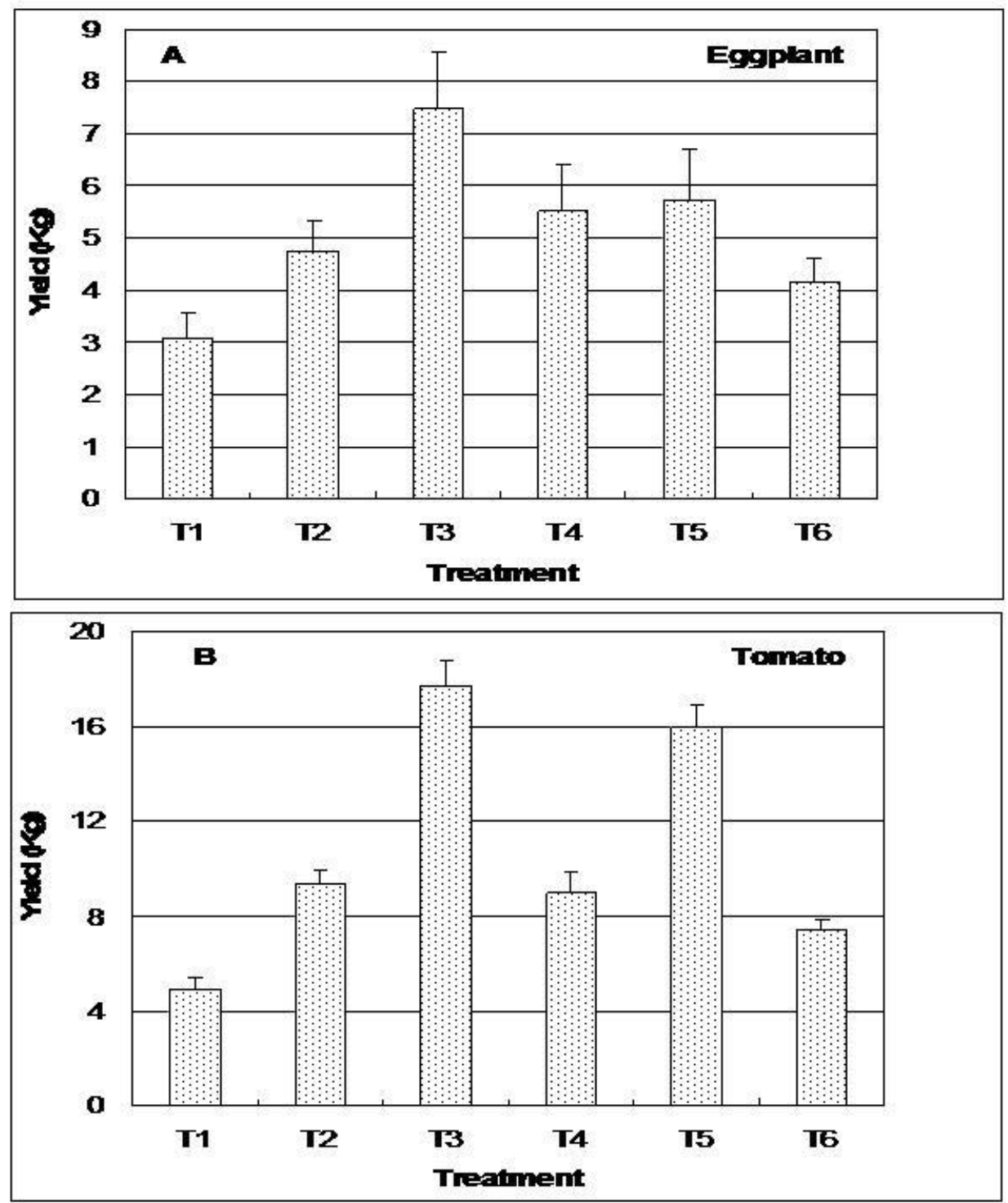

Fig. 4 - Marketable fruit yield of (A) eggplant and (B) tomato grown under six treatments. T1: no rice straw and no swine manure; T2: rice straw and low swine manure; T3: rice straw and high swine manure; T4: no rice straw, and low swine manure; T5 -no rice straw, and high swine manure; and T6: rice straw only. Bars on columns are standard errors of the mean.

\section{Discussion}

Biotic factors greatly contributed to the suppressiveness of the soil against $P$. infestans. The reduction in the incidence and severity of fruit rot in treatments with composted swine manure emanates on the biological activity and suppression of a wide array of microbial population developing during the composting process. These biotic factors also offer multiple mechanisms of biological suppression, thus, targeting a wide range of plant pathogens. Though the exact mechanisms of pathogen suppression is unknown, the composted animal manures are known to have more diverse microbial community and contain more fluorescent pseudomonads, heterothropic fungi, endospore-forming bacteria and oligotrophic bacteria which tend to offset the population of the pathogen (Diab et al. 2003). The presence of diverse microbial activity in combination with rice straw mulch further reduces the incidence and severity of the disease. The rice straw mulch prevents fruits from contacting infested soil by providing a barrier between the fruit and the free standing water (Mass 1984). Likewise, its rough surface reduces the splashing of water droplets bearing spores or sporangia (Madden 1990). Moreover, straw mulch also improved the soil fertility as it is decomposed towards the end of the season, 
also, it improves the visual appearance of healthy fruits making them clean and attractive due to absence of soil and other surface debris. The percentage of marketable fruits was also found to be higher in the straw mulch treated plots.

\section{Conclusion and Recommendation}

This study showed that incorporation of rice straw and swine manure can reduce Phytophthora fruit rot in tomato and eggplant. The merit of this approach is that it allows determining whether the pathogen was affected by the incorporated materials as measured by the levels of disease incidence and disease severity in the various treatments.

In general, disease incidence and disease severity were greatly reduced in eggplant and tomato plots treated with swine manure with concomitant increase in the marketable yields. Incorporation of rice straw and swine manure into field soil may serve as an effective option for reducing Phytophthora fruit rot not only in eggplant and tomato fruits but in other vegetables as well.

\section{Acknowledgement}

The authors wish to thank the American Phytopathological Society and JANE Foundation, USA for providing funds for the project.

\section{References}

Aryantha IP, Cross R, Guest DI. 2000 Suppression of Phytophthora cinnamomi in potting mixes amended with uncomposted and composted animal manures. Phytopathology 90, 775-782.

Bourke PM. 1964 - Emergence of potato blight. Nature 203, 805-808.

Chen W, Hoitink HA, Schmitthenner AF. 1987 - Factors affecting suppression of Pythium damping off using media amended with composts. Phytopathology 77, 755-760.

Chen W, Hoitink HA, Schmitthenner AF, Touvinen OH. 1988 - The role of microbial activity in suppression of damping off caused by Phythium ultimum. Phytopathology 78, 314-322.

Diab HG, Hu S. Benson DM. 2003 Suppression of Rhizoctonia solani on impatients by enhanced microbial activity in composted swine wasteamended potting mixes. Phytopathology 93, 1115-1123.

Drenth A, Sendall B. 2001- Practical guide to detection and identification of Phytophthora.Version 1.0. CRC for Tropical Plant Protection, Brisbane, Australia. 41p.

Ellis MA, Wilcox WF, Madden LV. 1998 Efficacy of metalaxyl, fosetylaluminum and straw mulch for control of strawberry leather rot caused by Phytophthora cactorum. Plant Disease 82, 329-332.

Fichtner EJ, Benson DM, Diab HG, Shew HD. 2004 - Abiotic and biological suppression of Phytophthora parasitica in a horticultural medium containing composted swine waste. Phytopathology 94, 780-788.

Hadar Y, Mandelbaum R. 1992 - Suppressive compost for biocontrol of soilborne plant pathogens. Phytoparasitica 20, S113-S116.

Madden LV, Ellis MA. 1990 - Effect of ground cover on splash dispersal of Phytophthora cactorum from strawberry fruits. J. Phytopathology 129, 170-174.

Mass JL. 1984. Compendium of strawberry diseases. American Phytopathological Society, St. Paul, MN, USA. 